Original Research Paper

\title{
Improving the Traffic Flow in Hot Arid Climate Areas by Implementing a Monorail Light Rail Transit System: Case of Kuwait
}

\author{
Taha Ahmed, Mohamed Salem, Ahmad Saad and Abdel Rahman Alaqqad \\ Department of Civil Engineering, Australian College of Kuwait, West Mishref, Kuwait
}

\author{
Article history \\ Received: 03-11-2020 \\ Revised: 18-01-2021 \\ Accepted: 22-01-2021 \\ Corresponding Author: \\ Taha Ahmed \\ Department of Civil \\ Engineering, Australian \\ College of Kuwait, West \\ Mishref, Kuwait \\ Email: t.ahmed@ack.edu.kw
}

\begin{abstract}
This study investigated the viability of establishing a monorail network system in Kuwait as an additional means of transportation to the current transportation systems. Two critical areas with high traffic demands were identified through the collected traffic data at the major intersections in these areas., These areas were Kuwait City (near the ministries area) and Al-Blajat street (known as the Arabian Gulf street). Traffic data and Level Of Service (LOS) of these areas were then analyzed using Synchro software, supported by site suitability studies conducted using ArcGIS Pro software. The most suitable locations of the proposed monorail systems were obtained by identifying the major Points Of Interest (POIs) in these areas. Synchro simulations of the systems with and without the monorail systems were performed. The results showed that the level of service at various intersections is improved, which can result in a significant reduction of the traffic congestion in these areas. The study also targeted different passengers and residents in the selected areas to evaluate the level of acceptance of the monorail system as an alternative transportation system in the state of Kuwait.
\end{abstract}

Keywords: Monorail, Level of Service, Traffic Congestion, Arid Climate, Light Rail Transit

\section{Introduction}

Kuwait's population is increasingly dependent on cars as the main mode of transportation; this is due to several factors, such as lack of maintenance of public transport services and their subsequent perception as 'unsafe' and as an 'inferior' mode of transportation. This, coupled with an explosion in the country's population due to increasing migration, has led to the prevalence of severe traffic jam that spans for large distances, which resulted in a large increase of travel times in a small metropolitan area. Using public transportation can help reduce the number of Single Operator Vehicles (SOVs) which can help in solving the traffic congestion problem. However, not all modes of public transportation are viable in a country with high records of temperature during the summer time. The state of Kuwait has what is known as an arid climate. According to the Köppen climate classification, arid (or desert) climate is known to have extreme dry heating conditions all year long with moderate winters that last only for a short time (Peel et al., 2007). In the summer months, the country regularly experiences temperatures exceeding $50^{\circ} \mathrm{C}\left(122^{\circ} \mathrm{F}\right)$ and was named the hottest place on Earth in 2016, with temperatures reaching $54^{\circ} \mathrm{C}$ $\left(130^{\circ} \mathrm{F}\right)$ (Michaelson, 2017). These extreme weather conditions present practical challenges to the Kuwaiti population. As an example, walking to the nearest bus station in the summer months can cause severe health issues (e.g.; heat stroke and severe dehydration). Solutions to traffic congestion has always been a subject of political debate in Kuwait. A recent report indicated that the Kuwait National Assembly's Interior and Defense Committee approved a proposal to suspend issuing new drivers licenses to expatriates for one year as a temporary solution to limit the number of personal vehicles. In addition, the government decided to reduce the subsidy on fuels to discourage SOVs and to promote carpooling; this has not been effective. Although Kuwait is keen to maintain the standards and conditions of its roadway network, several factors have led to the inability of the network to withstand the population's traffic 
demands. With the government's efforts proving futile, this study explores an alternative solution to reduce the demand of traveling cars on the roadway network by providing an alternative means of mass transportation. A viable and well-studied solution would help ensure a better economy, quality of life and lower Kuwait's overall carbon emissions by reducing domestic fuel consumption.

\section{Overview of Monorail Systems}

Rapid transit systems are considered an effective way of improving traffic flow and promoting urban sustainability by providing a convenient method of transportation through areas of high demand. Several rapid transit systems have been implemented worldwide, which include heavy rail systems (e.g., intra-nation rail systems), Light Rail Transit (LRT) (e.g., subways and underground metros) and bus routes (Miller et al., 2014). A relatively new form of LRT is the monorail transit system.

The monorail society defines the monorail as "a single rail serving as a track for passenger or freight vehicles. In most cases rail is elevated, but monorails can also run at grade, below grade or in subway tunnels. Vehicles are either suspended from or straddle a narrow guide way" (Miller et al., 2014). Early concepts for monorail systems as an alternative to conventional rail began in the 19th century (Schiller et al., 2010). Famous monorails have been constructed since 1957 (Siu, 2007). However, development of this technology into a commercial stage did not find success until the $20^{\text {th }}$ century. Despite the immense popularity monorails have had with the public, this form of transportation has been mainly relegated to world's fairs, airports and amusement parks (Vuchic, 2007).

The monorail system has been used in short roads less than other rail systems and new technology because of such advantages as lack of high traffic and of vocal pollution (Timan, 2015). The impossibility of using monorail infrastructure for other utility systems and less capacity for transporting passengers in comparison with other rail ones can be listed as major monorail system disadvantages, which should be noted to assess this system economically (Iwasaki, 2000). However, its speed of construction and its possibility for the cities with complex underground infrastructures, organic or natural underground limitations such as water table level are considered as main system advantages (Kennedy, 2013).

Moreover, monorail technology, systems, performance, development processes and financial characteristics prove to be superior to the best characteristics of other mass transportation modes (Siu, 2007). While being unencumbered by the institutional bureaucracy and fiscal limitations of public transportation agencies and authorities, the adaptability of monorail construction processes and operating characteristics to virtually any setting or environment permits monorails to be developed where other modes of transportation would be difficult (Timan, 2015). In addition, the significantly lower costs of right of way, construction, manufacturing, operation, maintenance and electrical power allow for cost-effective monorail development and services to be financed primarily through private and public-private entities and ventures (Ghafooripour et al., 2012).

\section{Types of Monorail Systems}

Monorails are divided into straddle and suspended-type systems (Fig. 1). Since the straddle-type travels by straddling the track, its center of gravity is situated above the track (Schiller et al., 2010). The suspended-type, on the other hand, is configured suspending from the track, with its center of gravity under the track (Abosuliman et al., 2011).
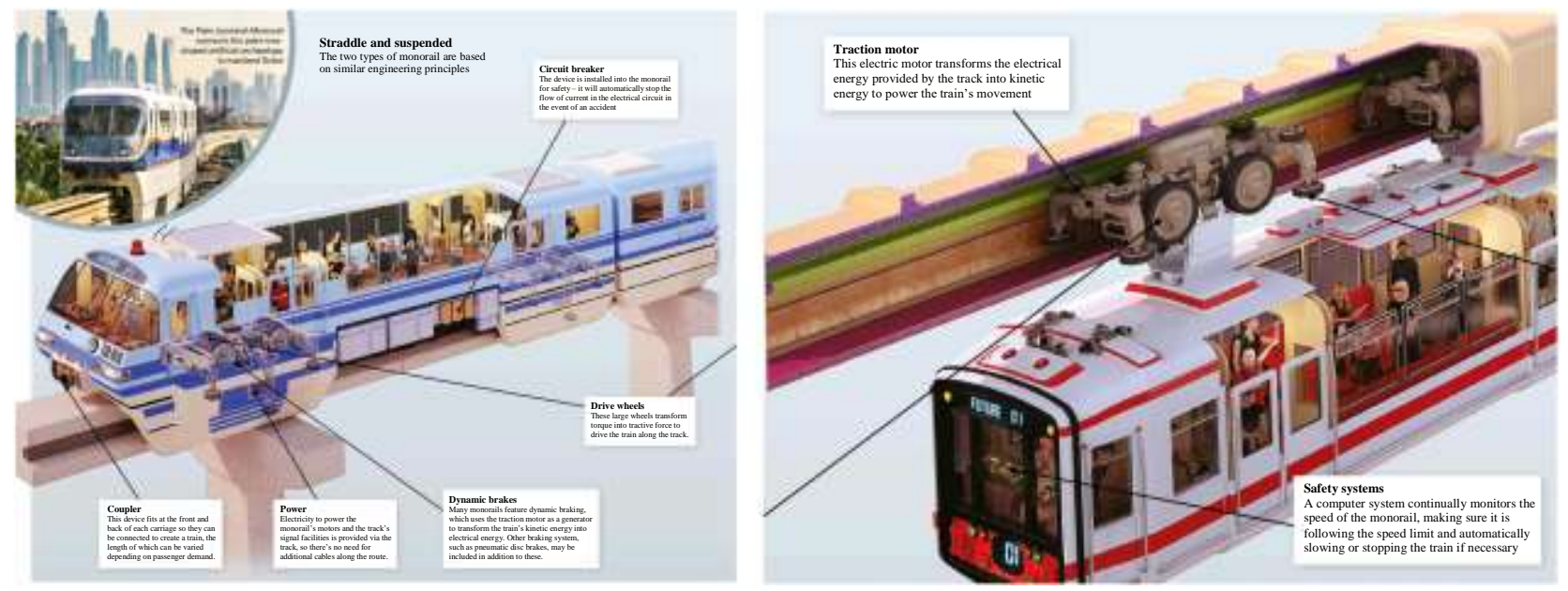

Fig. 1: Straddle (left) and suspended-type (right) monorail systems (Source: Schiller et al., 2010) 


\section{Benefits of Monorail Systems}

Monorail systems have a good reputation in the transit system world with a range of benefits. Those benefits are discussed in the following sections.

\section{Environmental Impact}

Most monorails are electrically powered, which makes them more environmentally friendly compare to other transit system. The more passengers using monorail systems, the less energy consumptions and carbon emissions transportation systems will have (Kikuchi and Onaka, 1988). Energy consumption and carbon emissions are reduced, not just during operation and running the systems, but also throughout the entire monorail cycle from manufacturing, operating and maintenance to the final dismantle (Ghafooripour et al., 2012).

\section{Traffic Decongestion}

Separated from all other transportation and urban systems by their nature and design, monorail systems do not interface or interfere with any other transportation mode, which makes them a perfect solution for traffic congestion (Miller et al., 2014).

\section{Safety}

Modern monorails preserve the most safety rules and regulations of any modes of transportation, having carried over billions of riders without a single passenger fatality (Iwasaki, 2000). Since monorails run around elevated tracks, accidents with surface traffic, structure as well as pedestrians are extremely rare (Das et al., 2013). Monorails are also safer as there is no risk of carriage obstruct, that means the system is a lot more efficient than other transportation modes (Schiller et al., 2010).

\section{Cost Effectiveness}

Monorail systems usually cost less than light rail systems, considerably less than heavy rail commuter railroads and much less than underground light rail or subway systems (Kennedy, 2013).

\section{Time Saving}

The monorails are normally elevated, above city streets traffic and therefore is safe from traffic congestion (Siu, 2007). It provides a quick and comfortable way to transport people around the city, which helps save traveling time.

\section{Adaptability}

Monorail systems can be constructed and remotely operated anywhere including existing urban settings and congested locations, where no other form of mass transportation can be effectively used or operated (Vuchic, 2007).

\section{Service Quality}

With $98-99 \%$ on-time performance reliability and nearly silent operation as passengers travel above it all, monorails consistently provide the best ride available to an ever-increasing constituency of riders (Kikuchi and Onaka, 1988).

\section{Innovation and Economic Development}

Monorail systems development and services offer $21^{\text {st }}$ Century industrial and economic alternatives and new solutions to the intractable congestion and accessibility constraints of existing transportation systems and the most attractive alternative to single-occupant commuter vehicle drivers (Ghafooripour et al., 2012).

\section{Examples of Rapid Transit Rail Systems in the Gulf Region}

Rapid transit rail systems have been used in several Gulf countries such as United Arab Emirates (UAE), Qatar and Saudi Arabia. UAE and Qatar have used similar rapid transit rail systems (also, known as Metro systems), however Saudi Arabia used a series of monorail routes along with the current transportation network infrastructure as an integrated system to accommodate the increasing traffic demand in major congested cities in the kingdom.

In 2009, the emirate of Dubai in UAE started using the Metro system to serve the increasing travel demand to the major existing and future employment centers, shopping malls and Dubai airport. Both monorail and Metro systems are very similar to each other in terms of operation and benefits. However, Metro systems require higher construction and maintenance cost. Nevertheless, the benefits of Dubai Metro system can be reflected on a similar monorail system (Mohammad et al., 2017) studied the impact of newly operated Dubai Metro on the sale transaction value of dwellings and commercial properties. The study concluded that, in addition to the traffic decongestion benefits, the metro system had a significantly positive impact on the sale values of both residential and commercial properties located within 701 to $900 \mathrm{~m}$ of any metro station.

Doha Metro in Qatar's capital city is one of the most advanced rapid rail transit systems in the world. It was officially opened for public in 2019. The Doha Metro system was designed with similar objectives to the ones achieved in Dubai Metro system. In addition, Doha Metro was meant to be a major part of a larger railway network, which comprises five modern and flexible railway systems integrated across the Persian Gulf (Railway Technology Newsletter, 2019). 
Recently, the Kingdom of Saudi Arabia has completed the major construction activities of a large rapid rail transit system to accommodate the high number of hajj pilgrims, citizens and business and leisure visitors to the cities of Jeddah, Makah and Madinah. The project included a series of monorail routes to connect between main areas in these cities. A study done by (Abosuliman et al., 2011), examined the effectiveness of this monorail project in the city of Jeddah and recommended that, an integrated monorail system using road infrastructure and serving a multitude of destinations should be used to achieve the maximum benefits of the proposed monorail system.

\section{Study Objectives}

This study aims at investigating the viability of establishing a monorail network in congested areas in Kuwait as a cost-effective and eco-friendly solution to alleviate the challenge of increasing traffic congestion in those areas. This study also aims to find the most suitable locations for the monorail routes and stations that can effectively reduce SOV traffic demand in congested areas.

\section{Main Design and Key Elements}

Monorail systems, like all transit systems, should be carefully developed to meet passenger needs and the limitations and opportunities of the local context (Miller et al., 2014). In this study, two major areas that suffer high level of traffic congestion were identified. The traffic data in each area was collected and the main traffic parameters were identified in order to be used to implement the proposed design.

\section{Area-1: Ministries Complex (MC)}

The first area is located in the heart of Kuwait City, where major government buildings are located. Named as "Ministries Complex (MC)", the area contains the headquarters of various governmental authorities and the ministries representative offices. Government facilities in this area experience high volumes of daily traffic, which leads to significant traffic delays during working hours on weekdays. Figure 2 shows a proposed monorail route for the first location, which includes four main stations and three sub-stations. Stations 1, 3 and 4 are placed at public parks, whereas Station 2 is located by the MC main entrance. The three sub-stations are distributed around the MC Building.

Area-1was selected to apply the monorail concept and show the positive impact of this system on a very congested area such as MC. The monorail system is anticipated to divert one-fifth of the thousands-plus vehicle trips per day in Kuwait City. The proposed monorail system could remove hundreds of vehicles from urban streets and freeways, while generating a good source of economic income per day that would provide ample economic support for construction, maintenance and operation of the monorail system.

The locations of stations were carefully selected to provide an efficient guide and friendly access for passengers with consideration to the rules of safety and comfortable transfer. Proposed stations are elevated and serviced by staircases and escalators. Additionally, the proposed locations provide easy connection with other modes of transportation and nearby residential, business and commercial areas and public service facilities. Figure 3 shows an overview of how the proposed station should look like.

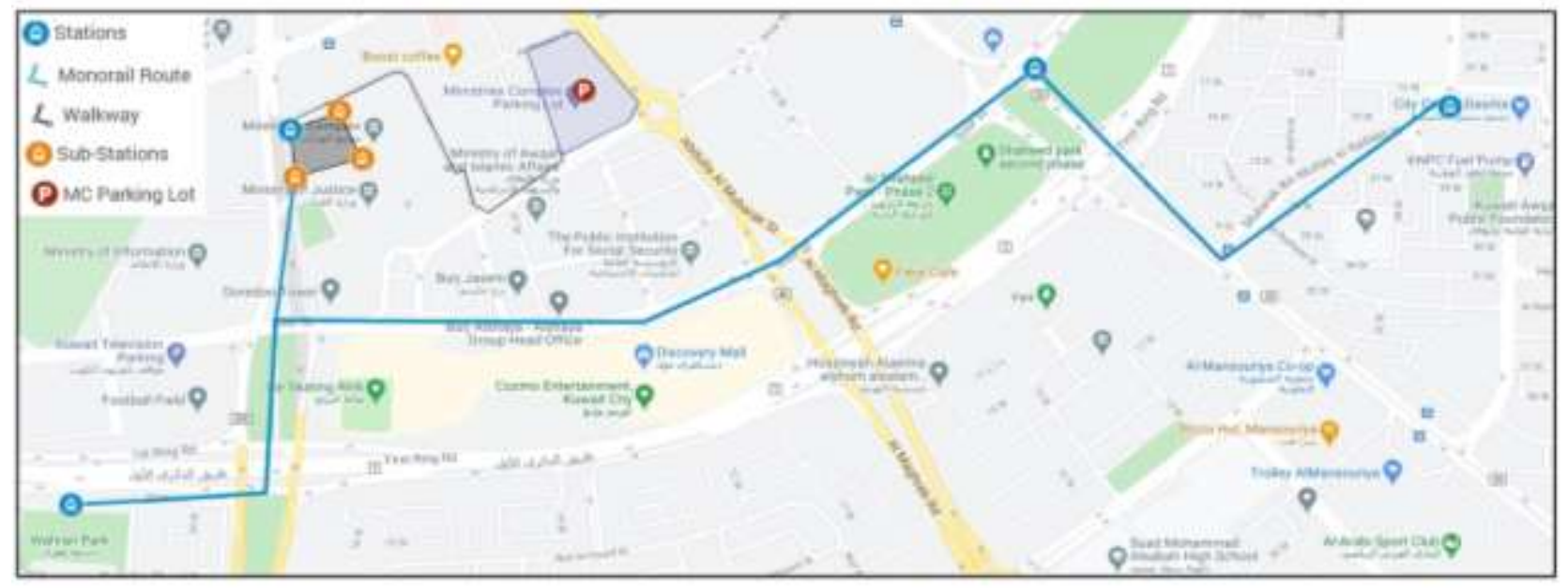

Fig. 2: Overview of the proposed monorail route and stations for the first location (Source: Google Maps, 2020) 


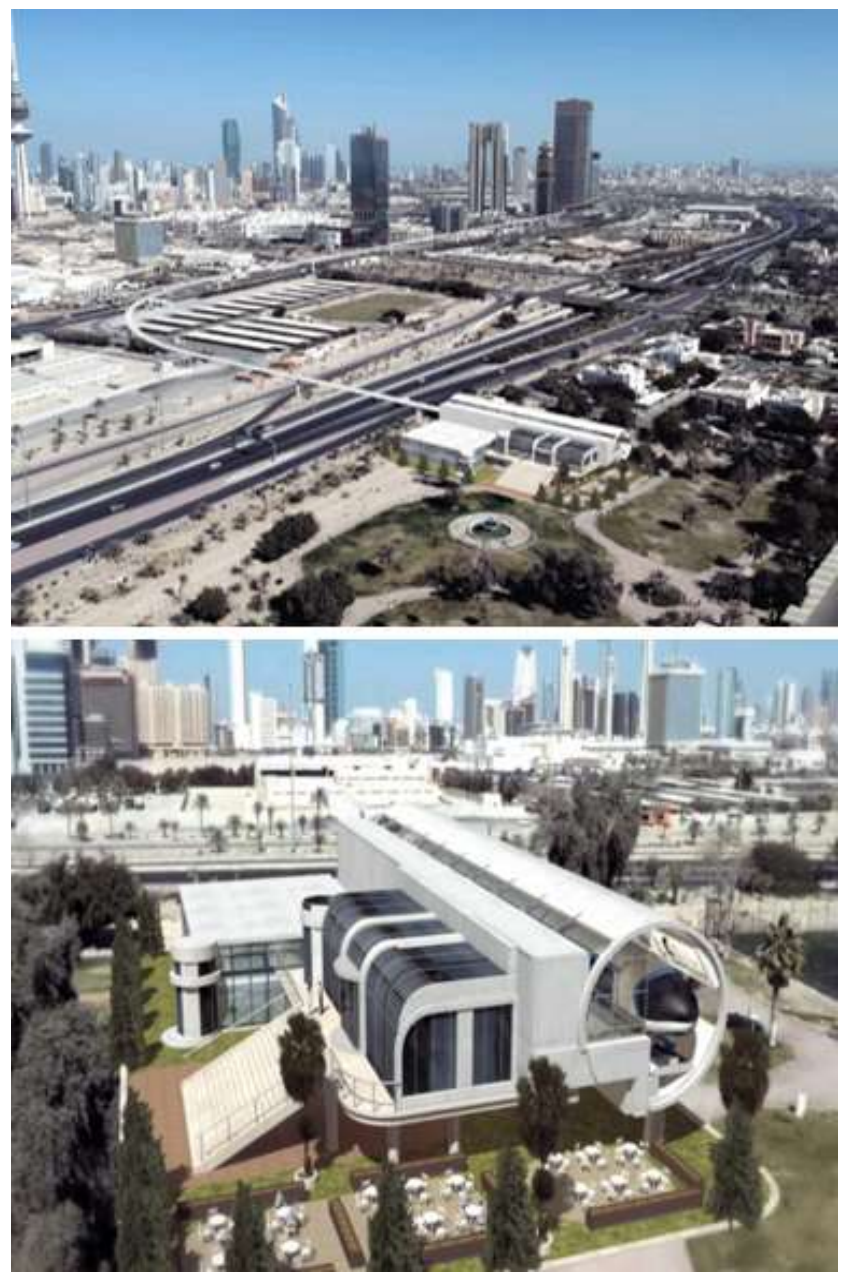

Fig. 3: Layouts of planned station location

\section{Area-2: Arabian Gulf Front}

The second area in this study is Al-Blajat Street along the Arabian Gulf. This area is known to have one of the highest traffic demands in Kuwait, especially during the weekends. The traffic parameters of this area are highly dependent on the locations of points of interest, which were identified along Al-Blajat Street. Point Of Interest (POI) in this study were defined as the final destination of travelers in this area. POIs included national attractions and cultural centers, which are located in area-2. The proposal for this route suggested placing the monorail stations by the nearest available public park adjacent to these POIs and placing others in close proximity to the POI itself. The proposed monorail has three train lines covering four different zones, which are shown in Fig. 4.

A site suitability study was conducted using ArcGIS Pro software (ESRI, 2019) to determine the ideal locations of the monorail stations and substations; the results of which are shown in Fig. 5.
Ideally, stations should be placed close to points of interest and population centers to encourage pedestrian access to the monorail. Offset distances from the POI $(>1 \mathrm{~km})$ and the roads $(>300 \mathrm{~m})$ were obtained then placed in a weighted sum function along with the population of each residential area. The formula placed $30 \%$ emphasis on proximity to the roads, $30 \%$ emphasis on population centers and $40 \%$ emphasis on the distance from POI.

The resulting layer was then reclassified into 9 scores, with 9 being the most suitable location for a monorail station and 1 being the least suitable location. Based on the suitability study results, four main stations and three sub-stations were selected for the monorail route. The main stations, named 1, 2, 3 and 4 (Fig. 4) are located along the proposed line. The sub-stations, named $\mathrm{A}, \mathrm{B}$ and $\mathrm{C}$, are located at the intermediate points of each line. Traffic data was only available for the second area, therefore traffic and LOS analyses were only conducted for the second area and are presented in this study. 


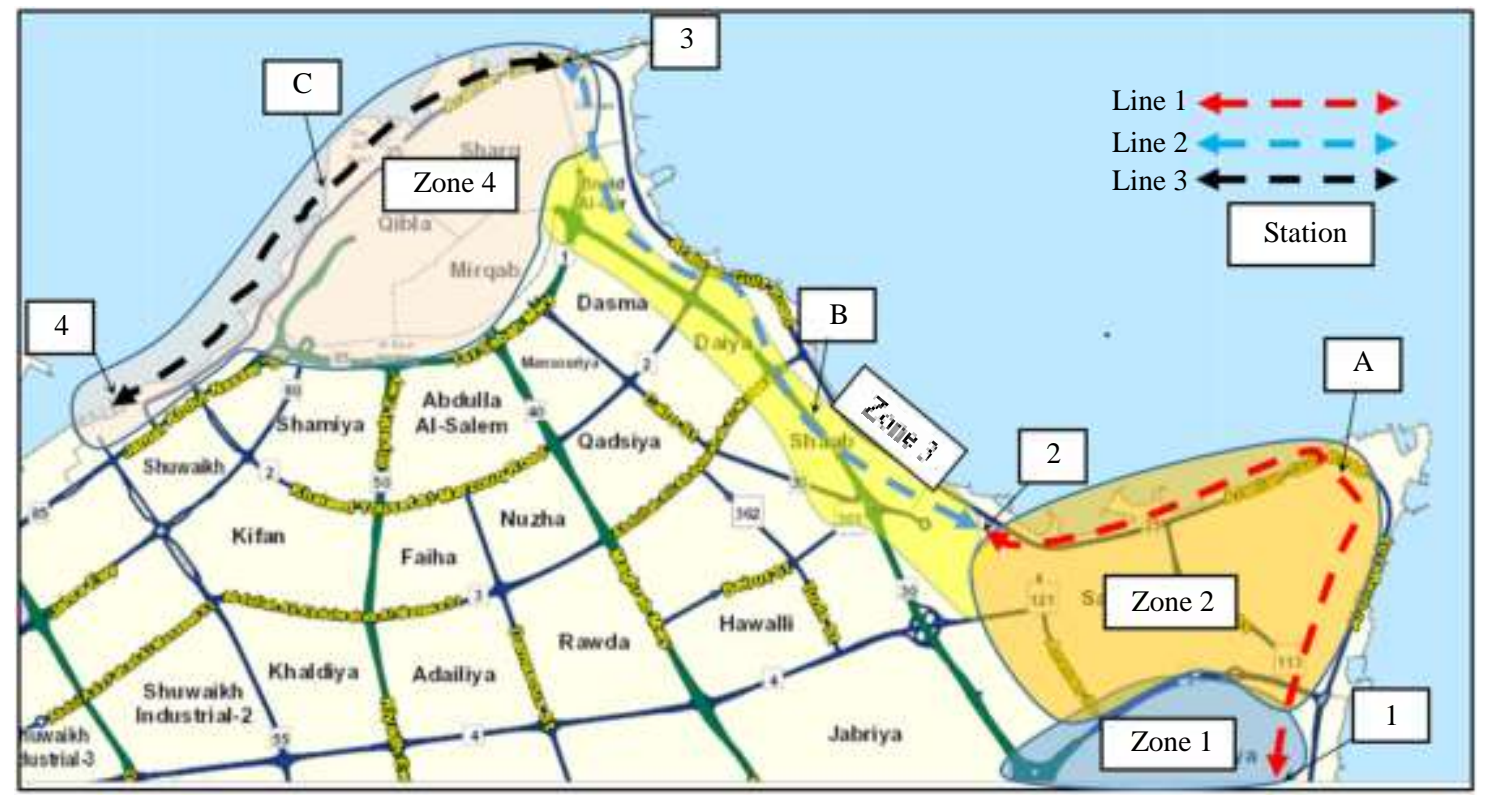

Fig. 4: Proposed monorail route and trip generation zones for Arabian gulf street (Source: PACI, 2019)

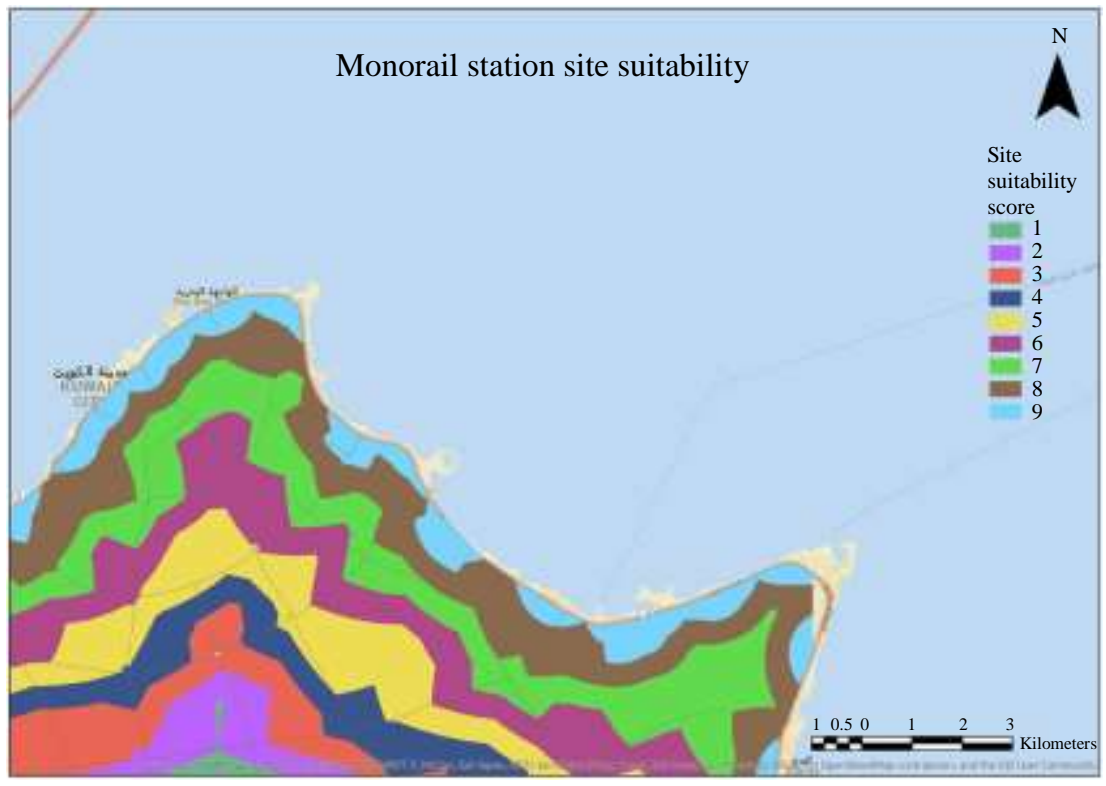

Fig. 5: Site suitability study to find ideal station locations for proposed monorail line (Source: ESRI, 2019)

\section{Trip Generation and Model Estimation}

Trip generators in the study area were represented by the POIs. To calculate the number of generated trips, the study area is divided into four main zones. Each zone had its points of interest, population and the number of trips. Due to a lack of sufficient data, the inverse-time method was used to calculate the number of trips between zones based on the actual travel times during peak hours.

The number of visitors going to each POI was assumed equal to the number of monorail users. The number of these trips was then directly subtracted from the traffic volume at the corresponding critical intersections on Al-Blajat Street. The distribution of trips generated between the specified zones during weekends and weekdays is shown in Table 1.

The results showed that the total number of generated trips during a typical weekend day (8,573 trips) is significantly higher than the number of generated trips during a typical weekday (5,640 trips), which can be attributed to the touristic nature of the area. For traffic analysis and monorail calculations, the number of trips generated on a typical weekend day was considered. 


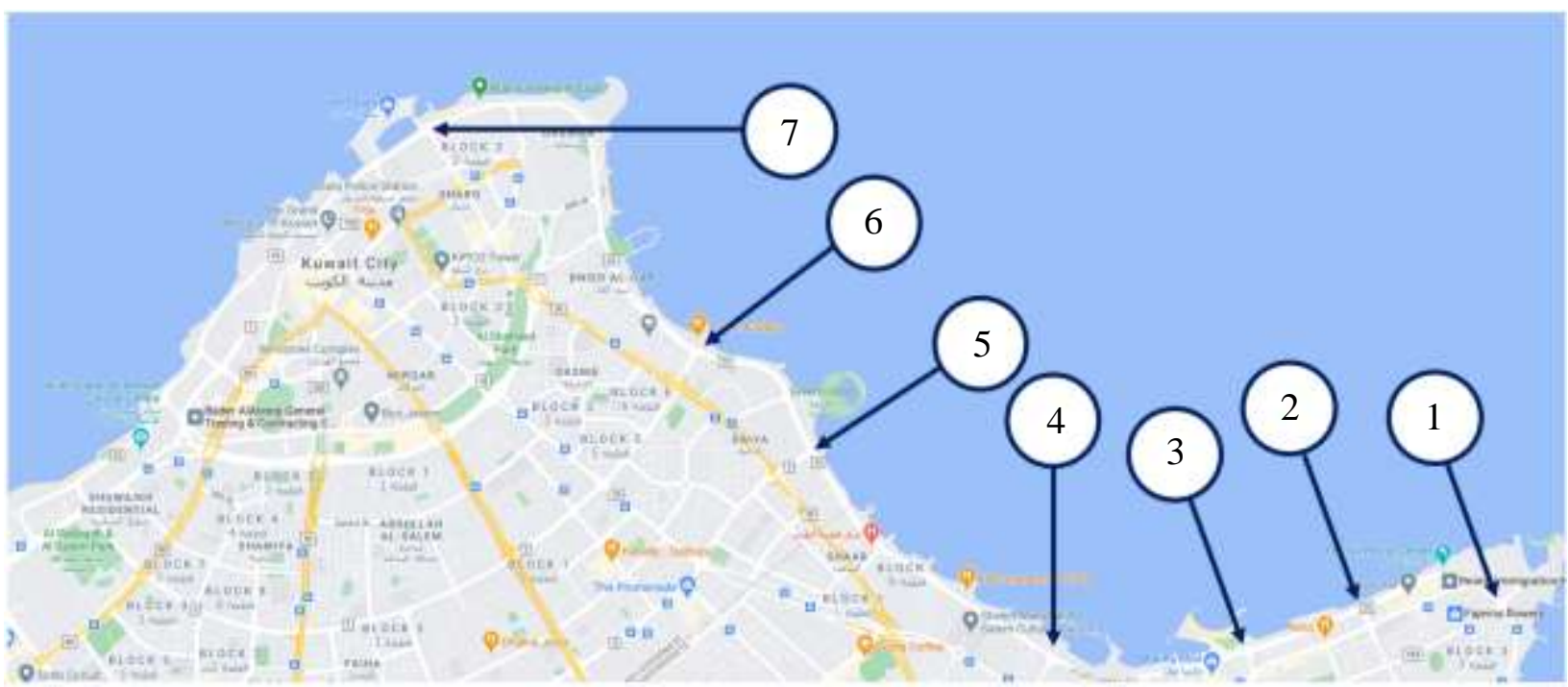

Fig. 6: Selected intersections for LOS analysis (Source: Google Maps, 2020)

Table 1: Distribution of trips between zones

\begin{tabular}{|c|c|c|c|c|c|c|}
\hline Zones & Number of trips/day & & Zone 1 & Zone 2 & Zone 3 & Zone 4 \\
\hline \multirow{2}{*}{1} & Weekend & 1170 & - & 370 & 220 & 180 \\
\hline & Weekday & 820 & - & 250 & 160 & 130 \\
\hline \multirow[t]{2}{*}{2} & Weekend & 1500 & 470 & - & 940 & 500 \\
\hline & Weekday & 800 & 250 & - & 500 & 270 \\
\hline \multirow[t]{2}{*}{3} & Weekend & 2300 & 720 & 1450 & - & 540 \\
\hline & Weekday & 1700 & 530 & 1070 & - & 400 \\
\hline \multirow[t]{2}{*}{4} & Weekend & 3603 & 460 & 860 & 850 & - \\
\hline & Weekday & 2320 & 300 & 550 & 550 & - \\
\hline \multirow[t]{2}{*}{ Total } & Weekend & 8573 & 1650 & 2680 & 2010 & 1220 \\
\hline & Weekday & 5640 & 1080 & 1870 & 1210 & 800 \\
\hline
\end{tabular}

Table 2: LOS analyses results

\begin{tabular}{|c|c|c|c|c|}
\hline No & Location & Description & LOS Before & LOS after \\
\hline 1 & Amr bin Al Aas St. (north) and Arabian Gulf Rd. & 3-way Intersection & $\mathrm{E}$ & $\mathrm{B}$ \\
\hline 2 & Qatar St. and Arabian Gulf Rd. & 3-way Intersection & $\mathrm{B}$ & A \\
\hline 3 & Hamad AlMubarak St. (north) and Arabian Gulf Rd. & 3-way Intersection & $\mathrm{F}$ & $\mathrm{C}$ \\
\hline 4 & Humoud Zaid AlKhaled St. and Arabian Gulf Rd. & 3-way Intersection & $\mathrm{F}$ & $\mathrm{D}$ \\
\hline 5 & Abdullah Ali AlMutawa St. (3rd Ring Road) and Arabian Gulf Rd. & 3-way Intersection & $\mathrm{D}$ & $\mathrm{C}$ \\
\hline 6 & Khaled Yousef AlMarzouq St. (2nd Ring Road) and Arabian Gulf Rd. & 3-way Intersection & $\mathrm{E}$ & $\mathrm{D}$ \\
\hline 7 & Jaber AlMubarak St. \& Arabian Gulf Rd. & 4-way Intersection & $\mathrm{F}$ & $\mathrm{C}$ \\
\hline
\end{tabular}

\section{Level of Service Analysis}

LOS is a qualitative ranking of the traffic operational conditions experienced by users of a facility under the specified roadway, traffic and traffic control conditions. The current Highway Capacity Manual (HCM) designates six levels of service ranging from $\mathrm{A}$ to $\mathrm{F}$, with the level of service A representing the best-operating conditions and level of service $\mathrm{F}$ representing the worst (Mannering and Washburn, 2013; TRB, 2010). Seven critical intersections were selected to conduct the LOS analysis to show the effects of implementing the monorail system on the LOS of the Arabian Gulf Street. Figure 6 shows the locations of the selected intersections for the LOS analysis.
As previously mentioned, the traffic volume in the selected intersections (Fig. 5) along the Al-Blajat street was reduced by the corresponding number of generated trips between zones, which are expected to be transferred to the proposed monorail system.

The LOS analyses were performed for the selected intersection before and after introducing the monorail to the Al-Blajat Street. The LOS analyses were performed using Synchro Software (Synchro Studio 9, 2017). Table 2 shows the LOS of the intersections before and after implementing the monorail system to the Arabian Gulf Street.

As seen in Table 2, the monorail system improved the LOS for all analyzed intersections by at least one level of service; it is worth noting that intersections 1,3 , 4 and 7 have improved by at least two levels of service. 
Hence, it can be concluded that introducing the monorail system can significantly improve the traffic flow and reduce traffic congestion along Al-Blajat Street.

\section{Socioeconomic Assessment}

As with any major infrastructure project, the socioeconomic benefits and impact of the monorail project should be carefully conducted and evaluated to ensure that the social objectives of the projects are met. The monorail's socioeconomic benefits should outweigh its impact to be considered a viable project worth pursuing. To conduct this assessment, one should consider several factors, such as the availability/acquisition of land needed for the project and whether any resettlement of the affected population shall take place. The assessment should also consider any future potential land use on or around the land that will be allocated to the project while taking into consideration current and future urban development plans of the country as a whole. Other socioeconomic factors related to this study include time savings, easing traffic congestion and cost savings to society (Kim, 2013; Avinash et al., 2018).

The current transportation system in Kuwait has been designed to be fossil fuel and automobile dependent. This is leading to greater numbers of vehicles on the roads network and a major growth in the associated fuel consumption costs, air pollution health impacts, congestion, road fatalities and carbon emissions. Cities in Kuwait are generally automobile focused. This phenomenon is reflected in the travel behavior of the society itself. The State has a very high proportion of private vehicle owning household (1.7 million privately owned cars as of 2018, according to Kuwait Central Statistical Bureau).

A social feasibility study needs to be conducted to see whether the population would be ready to make the move to use public transportation methods to reach POIs in the study area. To gauge this, a social media campaign was carried out on social media websites (Facebook, Instagram and Twitter) targeting all residents of Kuwait, where the monorail project was showcased and feedback on its viability and potential use were collected. The collected feedback was overwhelmingly positive; the majority of responders showed interest in using the service in the future.

Furthermore, one-on-one interviews were conducted in the first area (Kuwait City). The government complexes (Ministries Complex, Liberty Tower and the Public Institution for Social Security) located at the heart of the area in question was visited by the surveying team and the following data were collected from a representative population sample inside the locations:

- Trip origin

- Trip destination

- $\quad$ Mode of transit
- $\quad$ Parking location

- $\quad$ Trip time (minutes)

- Purpose

Seventy-five percent of the interviewed sample were visiting the government complexes with the purpose of business or transaction clearance. Ninety-five percent were using their personal cars, while five percent used taxis. The interviews found that it takes an average of 29 min to arrive at the government complexes and park their vehicle, while it could take $10 \mathrm{~min}$ to arrive to these destinations by monorail.

\section{Conclusion}

This study evaluated the idea of utilizing Light Rail Transit systems (specifically monorail systems) as an added means of transportation to enhance the level of service and reduce traffic jams at highly congested areas in the state of Kuwait. Two different areas were identified for the evaluation; these areas are Kuwait City and AlBlajat Street. Synchro software was used to run simulations of the traffic data at several intersections in the selected areas and found that the current levels of service is very low. Two proposed monorail systems were laid out by identifying the major points of interest in the areas of study using ArcGIS Pro Software. Levels of service were then obtained by running the Synchro simulations with the monorail systems. It was found that adding the monorail systems in the identified areas resulted in a significant improvement of the level of service, which reduces traffic congestion. In addition to the positive impact of the proposed system on the traffic performance, this system also contributes to the reduction of the $\mathrm{CO}_{2}$ emission as the numbers of SOVs are reduced. A survey to several passengers and residents in the study areas also showed a high level of acceptance to the idea.

\section{Author's Contributions}

Taha Ahmed: Conceptualization, data curation, formal analysis, writing-original draft, software.

Mohamed Salem: Data curation, resources, writingreview and editing.

Ahmad Saad: Data curation, Resources, Supervision, Writing, Validation, Visualization.

Abdel Rahman Alaqqad: Investigation, methodology, conceptualization, data curation, writing-review and editing, software.

\section{Ethics}

This article is original and contains unpublished material. The corresponding author confirms that all of the other authors have read and approved the manuscript and no ethical issues involved. 


\section{References}

Abosuliman, S. S., Kumar, A., Alam, F., \& Rasjidin, R. (2011). The conceptual design of monorail system in Jeddah City, Saudi Arabia. In International Conference on Applied Sciences, Mathematics and Humanities (pp. 288-295). Universiti Teknologi MARA.

Avinash, R. M., Chandra, S. J., \& Asadi, S. S. (2018). An integrated evaluation for feasibility study of monorail as Mass Rapid transit system for Vijayawada. International Journal of Mechanical Engineering and Technology, 9, 632-643. https:/www.iaeme.com/MasterAdmin/uploadfolder/ IJMET_09_03_065/IJMET_09_03_065.pdf

ESRI. (2019). ArcGIS Pro [computer software]. https://www.esri.com/en-us/arcgis/products/arcgispro/overview

Das, A. M., Ladin, M. A., Ismail, A. M. I. R. U. D. D. I. N., \& Rahmat, R. O. (2013). Consumers satisfaction of public transport monorail user in Kuala Lumpur. Journal of Engineering Science and Technology, $8(3), 272-283$.

Ghafooripour, A., Ogwuda, O., \& Rezaei, S. (2012). An efficient cost analysis of monorail in the Middle East using statistics of existing monorail and metro models. WIT Transactions on The Built Environment, 128, 241-252.

Google Maps. (2020). Kuwait Map. https://www.google.com.kw/maps/place/Kuwait/@2 $9.3578852,47.9676106,16.25 \mathrm{z} / \mathrm{data}=! 4 \mathrm{~m} 5 ! 3 \mathrm{~m} 4 ! 1 \mathrm{~s} 0 \mathrm{x}$ 3fc5363fbeea51a1:0x74726bcd92d8edd2!8m2!3d29 $.31166 ! 4 \mathrm{~d} 47.481766 ? \mathrm{hl}=\mathrm{en}$

Iwasaki, K. (2000). Research on Trucks for Small Straddle-type Monorails. Journal of Japan Monorail Association (JMA), (99), 44-47.

Kennedy, R. R. (2013). Considering Monorail Rapid Transit for North American Cities. Seattle Times. https://www.monorails.org/webpix\%202/RyanRKen nedy.pdf

Kikuchi, S., \& Onaka, A. (1988). Monorail development and application in Japan. Journal of advanced transportation, 22(1), 17-38.
Kim, M. (2013). Analysis of the Economic Feasibility of a Monorail on Mt. Bomun on Daejeon. Journal of the Korean Society for Railway, 16(3), 226-232.

Mannering, F. L., \& Washburn, S. S. (2013). Principles of Highway Engineering and Traffic Analysis. Wiley.

Michaelson, R. (2017). Kuwait's inferno: how will the world's hottest city survive climate change. The Guardian, 18.

Miller, P., Wirasinghe, S. C., Kattan, L., \& de Barros, A. (2014). Monorails for sustainable transportation-a review. GEN, 181, 1.

Mohammad, S. I., Graham, D. J., \& Melo, P. C. (2017). The effect of the Dubai Metro on the value of residential and commercial properties. Journal of Transport and Land Use, 10(1), 263-290.

Peel, M. C., Finlayson, B. L., \& McMahon, T. A. (2007). Updated world map of the Köppen-Geiger climate classification.

PACI. (2019). Public Authority for Civil Information (PACI). Kuwaiti Finder Application. (2019). 'Kuwait Map.'

Railway Technology Newsletter. (2019). Doha Metro. https://www.railway-technology.com/projects/dohametro

Schiller, P. L., Bruun, E. C., \& Kenworthy, J. R. (2010). An introduction to sustainable transportation: Policy, planning and implementation. Earthscan.

Siu, L. K. (2007). Innovative lightweight transit technologies for sustainable transportation. Journal of Transportation Systems Engineering and Information Technology, 7(2), 63-70.

Synchro Studio 9. (2017). Synchro Studio 9 [computer software]. https://www.trafficware.com/synchro.html

Timan, P. (2015). Why Monorail Systems Provide a Great Solution for Metropolitan Areas. Urban Rail Transit, 1(1), 13-25.

TRB. (2016). Highway capacity manual 6th edition: A guide for multimodal mobility analysis. Transportation Research Board.

Vuchic, V. R. (2007). Urban transit systems and technology. John Wiley \& Sons. 